\title{
Effect of Attending Practice Style on Generic Medication Prescribing by Residents in the Clinic Setting: An Observational Study
}

\author{
Kira L. Ryskina, $M D^{1,2}$, C. Jessica Dine, MD, MSHPR ${ }^{2,3}$, Esther J. Kim, BS ${ }^{7}$, Tara F. Bishop, MD, MPH ${ }^{4,5}$, \\ and Andrew J. Epstein, $P h D^{1,2,6}$
}

\begin{abstract}
'Division of General Internal Medicine, Perelman School of Medicine, University of Pennsylvania, Philadelphia, PA, USA; ${ }^{2}$ Leonard Davis Institute of Health Economics, University of Pennsylvania, Philadelphia, PA, USA; ${ }^{3}$ Division of Pulmonary and Critical Care, University of Pennsylvania, Philadelphia, PA, USA; ${ }^{4}$ Division of Health Outcomes and Effectiveness, Department of Public Health, Weill Cornell Medical College, New York, NY, USA; ${ }^{5}$ Department of Medicine, Weill Cornell Medical College, New York, NY, USA; ${ }^{6}$ Department of Veterans Affairs Center for Health Equity Research and Promotion, Philadelphia VA Medical Center, Philadelphia, PA, USA.
\end{abstract}

BACKGROUND: Despite increased emphasis on costconsciousness in graduate medical training, there is little empirical evidence of the role of attending physician supervision on resident practice in this area.

OBJECTIVE: To study whether the prescribing practices of attendings influence residents' prescribing of brand-name statin medications in the ambulatory clinic setting.

DESIGN AND PARTICIPANTS: A retrospective study of statin prescriptions by residents at two internal medicine residency programs, using electronic medical record data from July 2007 through November 2011.

MAIN MEASURES: We estimated multivariable hierarchical logistic regression models to assess the independent effect of the supervising attending's rate of brand-name prescribing in the preceding quarter on the likelihood of a resident prescribing a brand-name statin.

KEY RESULTS: The sample included 342 residents and 58 attendings, accounting for 10,151 initial statin prescriptions, including 3,942 by residents. Brand-name statins were prescribed in about onefourth of encounters. After adjusting for patient-, physician-, and practice-level factors, the supervising attendings' brand-name prescribing rate in the quarter preceding the encounter was positively associated with a postgraduate year (PGY)-1 resident's prescribing a brand-name statin, but not for PGY-2 or PGY-3 residents. For PGY-1 residents, the adjusted probability of a resident prescribing a brand-name statin ranged from $22.6 \%$ (95\% CI 17.3-28.0\%, p < $0.001)$ for residents supervised by an attending who prescribed $<20 \%$ brand-name statins in the previous quarter to $41.6 \%$ (95\% CI 24.6-58.5\%, p < $0.001)$ for residents supervised by an attending who prescribed at least $80 \%$ brand-name statins in the previous quarter. A higher PGY level was associated with brand-name prescribing (aOR 2.07, $95 \% \mathrm{CI}$ 1.28-3.35, $\mathrm{p}=0.003$ for PGY-2; aOR 2.15, $95 \% \mathrm{CI}$ $1.31-3.55, \mathrm{p}=0.003$ for PGY-3, vs. PGY-1).

CONCLUSIONS: Supervising attendings' prescribing of brand-name medications may have a significant influence on PGY-1 residents' prescribing of brand-name medications, but not on prescribing by more senior residents.

Published online July 15, 2015
KEYWORDS: Medical education; Graduate; Practice variation; Health care costs; Drugs; Medical culture.

J Gen Intern Med 30(9):1286-93

DOI: $10.1007 / \mathrm{s} 11606-015-3323-5$

(c) Society of General Internal Medicine 2015

\section{BACKGROUND}

With healthcare spending outpacing the rate of economic growth, ${ }^{1}$ cost-effective care is receiving increased attention from education experts and policymakers. ${ }^{2-5}$ Academic medical centers face growing pressure to develop processes to reduce unnecessary and low-value care and to evaluate resident competency in this area of practice. In 2012, the practice of cost-effective care was incorporated into the training milestones for internal medicine residency programs by the Accreditation Council for Graduate Medical Education (ACGME). ${ }^{6}$ The 2014 Institute of Medicine report on graduate medical education financing echoed earlier recommendations to transition to performance-based reimbursement for academic medical centers, with an emphasis on reducing healthcare costs. $^{7-9}$

Since residents care for patients in the course of their training under the supervision of attending physicians, we might expect that residents would adopt their attendings' practice style. A few studies have documented the impact of residents on care decisions and variation in practice styles across residents. ${ }^{10-13}$ In the inpatient setting, residents have been found to independently account for a considerable proportion of variation in hospital length of stay and ancillary resource use, ${ }^{10}$ including the ordering of laboratory tests. ${ }^{11}$ In the ambulatory setting, a study of resident prescribing practices found considerable variation in generic vs. brand-name statin prescribing by residents after controlling for the effect of the supervising attending. ${ }^{12}$ After completing training, less experienced physicians had higher overall cost profiles than more experienced physicians. ${ }^{13}$ Although these findings suggest that residents do not perfectly mirror their attending physicians' practice patterns, the relationship between attending physicians and the practice of residents that they supervise has not been studied directly. 
We sought to investigate the relationship between attending and resident practice in the setting of statin prescribing, an opportunity for cost-effective care. The prescribing of statins was the costliest of the "Top 5" interventions identified in 2010 by the National Physician Alliance as the best opportunities to promote stewardship of healthcare resources in daily practice. ${ }^{14}$ The recommendation to use generic statins rather than brandname statins when initiating lipid-lowering therapy was based on long-standing evidence; ${ }^{15,16}$ however, there was considerable variation in the use of brand-name vs. generic statins during this time, ${ }^{17}$ with brand-name prescribing estimated to account for $\$ 5.8$ billion in potentially unnecessary spending in $2009 .{ }^{18}$

\section{Objectives}

Our study evaluates the role of attending physicians on their residents' decisions to prescribe generic vs. brand-name statins in the resident clinic setting. Based on the assumption that residents start training with minimal experience with or preference among prescription drugs, we hypothesized that attending practice styles were influential on residents' brandname vs. generic statin prescribing overall, but that the effect of attending supervision was greatest early in training and attenuated as residents accumulated experience.

\section{METHODS}

\section{Design and Participants}

We performed a retrospective analysis of a combined longitudinal dataset of statin prescribing by resident and attending physicians in the ambulatory practices at two East Coast academic medical centers between July 2007 and November 2011. Data included the resident and attending practice of the New York Presbyterian/Weill Cornell (NYP/WC) internal medicine residency program in New York, NY, and three resident and attending practices of the University of Pennsylvania internal medicine residency program in Philadelphia, PA. Electronic medical record data were obtained from the Epic Systems (Venona, WI, USA) databank at each institution. All in-person attending-patient and resident-patient encounters where a statin was initiated for an established clinic patient were included. All in-person resident encounters were precepted and co-signed by an attending, and the attending-resident pairs were captured for each resident-written prescription for a statin. We evaluated the specific attending-resident pairings involved in each patient-resident encounter. Only one attending supervised the resident during each encounter. To measure the brand-name statin prescribing rate for an attending, all initial statin prescriptions written by the attending physicians for patients seen by them without a resident were evaluated.

\section{Sample Selection}

We excluded refills (determined based on the existence of a prior statin prescription for the same patient within 18 months of the index script) and prescriptions written during a patient's initial visit to the practice (because we were unable to discern whether these were new or refill). Switches between different statins were considered refills and excluded as well. Prescriptions that were later changed or discontinued were included in the analysis, as our aim was to study initial statin prescribing behavior by the resident and not statin use by patients. Prescriptions occurring more than 18 months after the preceding one were treated as new prescriptions. We conducted sensitivity analyses excluding any refilled prescriptions (even those renewed more than 18 months after the initial script) to evaluate the effect of differences in the definition of an initial statin prescription on our results.

The study period ended November 30, 2011, which preceded generic availability of atorvastatin. Therefore, all prescriptions for atorvastatin and rosuvastatin during the study period were coded as brand-name prescriptions. Prescriptions that were written for other brand-name statins with instructions to "dispense as written" were also coded as brand-name. All other statin prescriptions were identified as generic.

\section{Analysis}

The analysis consisted of two steps. First, we examined physician-level proportions of brand-name medications prescribed per quarter by residents and by attending physicians. The quarterly rate of brand-name statin prescribing for each physician (resident or attending) was defined as the proportion of brand-name statin prescriptions over the total number of statin prescriptions written that quarter. For attending physicians, only prescriptions written for patients seen without a resident were included in calculating their brand-name prescribing rate. Second, we conducted an encounter-level analysis where the outcome was whether the resident prescribed a brand-name or generic statin.

We estimated a multivariable hierarchical logistic regression model that accounted for the nesting of patients within physicians, with a physician random effect to evaluate the effect of attending brand-name prescribing style during the quarter prior to the encounter, on the odds of a brand-name statin prescribed by the resident in an encounter supervised by that attending. The independent variables of interest were the supervising attending's rate of brand-name prescribing in the preceding quarter interacted with the resident's year of residency. To ease interpretation, the attending's lagged rate of brand-name prescribing was modeled as a categorical variable representing $<20 \%, 20-39 \%, 40-59 \%, 60-79 \%$, and $>79$ $\%$ brand-name prescribing rates. We adjusted for practice characteristics (practice site), patient characteristics (age, gender, comorbidities, tobacco use, and insurance type), resident 
characteristics (year in training [PGY level]), cohort year (to control for time trends), and whether the resident was the patient's designated primary care provider) in the model. Observations with missing values were dropped from the model. (Of the 3942 prescription encounters by a resident during the study period, 1314 were missing the supervising attending's brand-name prescribing rate for the previous quarter and 46 prescription encounters were missing other variables.) The predictive marginal effects of attending brandname statin prescribing rate in the preceding quarter on the probability of a brand-name statin prescribed by the resident were estimated at each PGY level.

All analyses were conducted using STATA version 13.1 (StataCorp, College Station, TX, USA). This study was reviewed and approved by the University of Pennsylvania and Weill Cornell Medical College institutional review boards.

\section{RESULTS}

\section{Participants}

Of the 400 physician participants in our sample, 342 were residents and 58 were attending physicians. Over the full study period, residents wrote 12 statin prescriptions on average (SD 9.7), whereas attending physicians wrote 108 statin prescriptions on average (SD 82.0). Resident and attending physicians had similar brand-name prescribing rates; residents on average wrote $24.9 \%$ (SD $24.2 \%$ ) of new statin prescriptions for brand-name medications, while attendings on average wrote prescriptions for brand-name statins in $25.7 \%$ (SD 23.3\%) of encounters. Compared to residents' patient panels, attending physicians' patient panels had a higher proportion of patients over the age of 65 (42.4 vs. $31.0 \%, \mathrm{p}<0.001)$ and covered by Medicare (39.6 vs. $33.3 \%, p<0.001$ ), but a smaller proportion of patients with coronary artery disease ( 7.9 vs. $11.3 \%$, p $<0.001$ ), diabetes (34.0 vs. $42.5 \%, \mathrm{p}<0.001$ ), or tobacco use
(4.7 vs. $9.1 \%, p<0.001$ ). Table 1 describes physician participant characteristics.

\section{Variation in Brand-Name Prescribing}

Table 2 describes differences between brand-name and generic prescriptions written by the residents. Of the 2,582 statin prescriptions written by residents during the study period, more brand-name statin prescriptions were written by PGY-2 and PGY-3 compared to PGY-1 residents (28.1 \% for PGY-1, $39.8 \%$ for PGY-2, and $32.0 \%$ for PGY-3, p = 0.013). Compared to generic statin prescriptions, most brand-name prescriptions were written for patients with private insurance (44.6 vs. $19.7 \%$ ) or Medicare (43.6 vs. $34.9 \%$ ), whereas over $45 \%$ of generic prescriptions (vs. $11.8 \%$ of brand-name) were written for patients without insurance, missing insurance information, or on Medicaid ( $\mathrm{p}<0.001)$.

Figure 1 depicts the variation in brand-name prescribing among residents with at least two prescriptions for a statin during the study period $(n=303)$. About half of these residents $(\mathrm{n}=155,51 \%)$ prescribed brand-name statins in less than $20 \%$ of encounters, 39 (13\%) residents prescribed brand-name statins 20-39\% of the time, 59 (19 $\%$ ) prescribed brand-name statins $40-59 \%$ of the time, 38 (13\%) prescribed brand-name statins $60-79 \%$ of the time, and $12(4 \%)$ prescribed brand-name statins in 80 $\%$ or more of patient encounters.

\section{Lagged Attending Prescribing Style}

Nearly half (47\%) of all statin prescriptions written by residents were written under the supervision of attendings who prescribed brand-name statins at a rate of $<20 \%$ in the quarter prior to the encounter. A larger proportion $(60.3 \%)$ of generic statin prescriptions were written under the supervision of attendings with a brandname prescribing rate $<20 \%$ for the previous quarter, while residents supervised by attendings with a brand-

Table 1 Study Population Characteristics at Individual Physician Level

\begin{tabular}{|c|c|c|c|}
\hline & Total & Attendings & Residents \\
\hline No. of physicians & 400 & 58 & 342 \\
\hline No. of scripts per physician, mean (SD) & $25.6(46.6)$ & $107.5(82.0)$ & $12.2(9.7)$ \\
\hline No. of residents supervised per attending, mean (SD) & - & $39.1(45.5)$ & - \\
\hline Brand-name prescribing rate, \% mean (SD) & $25.0(24.0)$ & $25.7(23.3)$ & $24.9(24.2)$ \\
\hline \multicolumn{4}{|l|}{ Patients, $\%$ mean (SD) } \\
\hline Age $65+$ years & $32.6(18.0)$ & $42.4(12.1)$ & $31.0(18.3)$ \\
\hline Male gender & $41.4(20.6)$ & $37.0(17.7)$ & $42.1(21.0)$ \\
\hline \multicolumn{4}{|l|}{ Comorbidities } \\
\hline CAD & $10.8(11.9)$ & $7.9(5.5)$ & $11.3(12.6)$ \\
\hline CVA & $3.9(8.4)$ & $2.9(4.9)$ & $4.1(8.9)$ \\
\hline Hypertension & $62.5(19.9)$ & $61.0(13.3)$ & $62.8(20.8)$ \\
\hline Hyperlipidemia & $69.5(20.8)$ & $71.3(14.9)$ & $69.1(21.7)$ \\
\hline Diabetes & $41.3(19.3)$ & $34.0(11.4)$ & $42.5(20.1)$ \\
\hline Tobacco use & $8.4(12.4)$ & $4.7(6.1)$ & $9.1(13.0)$ \\
\hline \multicolumn{4}{|l|}{ Insurance } \\
\hline Private & $28.1(28.4)$ & $28.3(22.3)$ & $26.8(25.4)$ \\
\hline Medicare & $34.2(19.5)$ & $39.6(9.7)$ & $33.3(20.5)$ \\
\hline Medicaid & $3.9(7.6)$ & $4.4(8.1)$ & $1.3(2.1)$ \\
\hline Missing & $34.9(33.6)$ & $30.8(26.3)$ & $35.6(34.7)$ \\
\hline
\end{tabular}


Table 2 Characteristics of Prescriptions Written by Residents $(n=2582)$

\begin{tabular}{|c|c|c|c|c|}
\hline & Total, $\mathrm{n}(\%)(\mathrm{n}=\mathbf{2 5 8 2})$ & $\begin{array}{l}\text { Brand-name, } \\
\text { n }(\%)(n=899)\end{array}$ & $\begin{array}{l}\text { Generic, } n(\%) \\
(\mathrm{n}=1683)\end{array}$ & p value \\
\hline \multicolumn{5}{|l|}{ PGY level } \\
\hline PGY-1 & $822(31.8)$ & $253(28.1)$ & $569(33.8)$ & \multirow{3}{*}{0.013} \\
\hline PGY-2 & $969(37.5)$ & $358(39.8)$ & $611(36.3)$ & \\
\hline PGY-3 & $791(30.6)$ & $288(32.0)$ & $503(29.9)$ & \\
\hline \multicolumn{5}{|l|}{ By study year } \\
\hline $2007-2008$ & $92(3.6)$ & $11(1.2)$ & $81(4.8)$ & \multirow[t]{5}{*}{$<0.001$} \\
\hline $2008-2009$ & $190(7.4)$ & $9(1.0)$ & $181(10.8)$ & \\
\hline $2009-2010$ & $1143(44.3)$ & $529(58.8)$ & $614(36.5)$ & \\
\hline 2010-2011 & $1012(39.2)$ & $328(36.5)$ & $684(40.6)$ & \\
\hline $2011-2012$ & $145(5.6)$ & $22(2.5)$ & $123(7.3)$ & \\
\hline \multicolumn{5}{|c|}{ Brand-name prescribing rate of attending physician in previous quarter } \\
\hline$<20 \%$ & $1213(47.0)$ & $198(22.0)$ & $1015(60.3)$ & \multirow[t]{5}{*}{$<0.001$} \\
\hline $20-39 \%$ & $304(11.8)$ & $135(15.0)$ & $169(10.0)$ & \\
\hline $40-59 \%$ & $600(23.2)$ & $319(35.5)$ & $281(16.7)$ & \\
\hline $60-79 \%$ & $392(15.2)$ & $207(23.0)$ & $185(11.0)$ & \\
\hline$>79 \%$ & $73(2.8)$ & $40(4.5)$ & $33(2.0)$ & \\
\hline \multicolumn{5}{|l|}{ Insurance type } \\
\hline Private & $732(28.4)$ & $401(44.6)$ & $331(19.7)$ & \multirow[t]{4}{*}{$<0.001$} \\
\hline Medicare & $980(38.0)$ & $392(43.6)$ & $588(34.9)$ & \\
\hline Medicaid & $134(5.2)$ & $63(7.0)$ & $71(4.2)$ & \\
\hline Missing & $736(28.5)$ & $43(4.8)$ & $693(41.2)$ & \\
\hline
\end{tabular}

name prescribing rate $\geq 20 \%$ prescribed a larger proportion $(78.0 \%)$ of brand-name statins (Table 2).

\section{Effect of Attending Style in Previous Quarter and Generic Prescribing by Resident}

Table 3 shows the adjusted odds of a resident prescribing a brand-name statin based on attending brand-name prescribing rate and the resident's PGY level after adjusting for patient-, physician-, and practice-level factors. For PGY-1 residents, the attending brand-name prescribing rate in the quarter prior to the encounter was associated with higher odds of a resident prescribing a brand-name statin (adjusted odds ratios [aOR] ranging from $2.26,95 \% \mathrm{CI} 1.34-3.81, \mathrm{p}=0.002$, for attendings who prescribed brand-name statins $40-59 \%$ of the time, to aOR 3.40, $95 \%$ CI 1.10-10.50, $\mathrm{p}=0.034$, for attendings who prescribed brand-name statins at least $80 \%$ of the time, compared to attendings who prescribed brand-name statins $<$ $20 \%$ of the time) (Table 3). The effect of the attending practice style was not significantly associated with brand-name prescribing by PGY-2 or PGY-3 residents (Table 3).

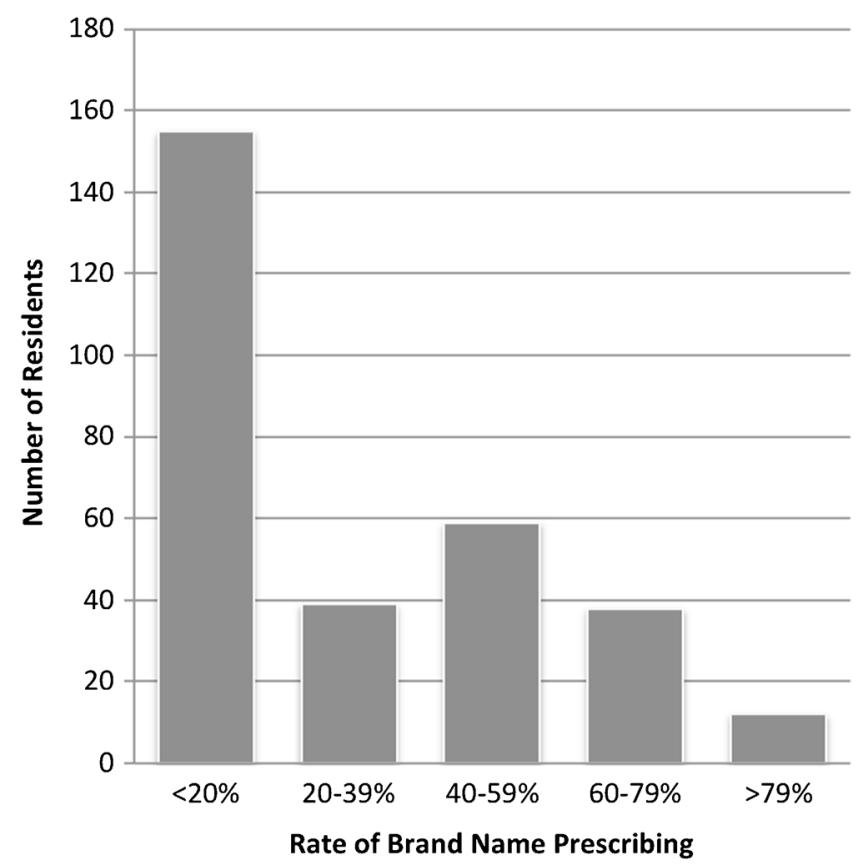

Fig. 1 Variation in brand-name statin prescribing for residents with $>1$ prescription $(\mathrm{n}=\mathbf{3 0 3})$. This histogram shows the distribution of residents by quintile of brand-name statin prescribing for residents with more than one statin prescription during the study period. The $x$-axis represents proportion of statin prescriptions that were written for brand-name statins. The $y$-axis depicts the number of residents in each quintile. 
Table 3 Effect of Supervising Attending's Brand-Name Statin Prescribing Rate on the Odds of a Brand-Name Statin Prescribed by the Resident $(n=2582)$

\begin{tabular}{|c|c|c|c|c|c|}
\hline \multirow{2}{*}{$\begin{array}{l}\text { PGY level of resident } \\
\text { PGY-1 }\end{array}$} & \multirow{2}{*}{$\begin{array}{l}\text { Brand-name prescribing } \\
\text { rate of supervising attending } \\
<20 \%\end{array}$} & \multirow{2}{*}{$\begin{array}{l}\text { OR } \\
1.0\end{array}$} & \multicolumn{2}{|c|}{$95 \%$ CI } & p value \\
\hline & & & - & - & - \\
\hline & $20-39 \%$ & 1.51 & 0.85 & 2.70 & 0.16 \\
\hline & $40-59 \%$ & 2.26 & 1.34 & 3.81 & 0.002 \\
\hline & $60-79 \%$ & 2.33 & 1.33 & 4.08 & 0.003 \\
\hline & $>79 \%$ & 3.40 & 1.10 & 10.50 & 0.034 \\
\hline \multirow[t]{5}{*}{ PGY-2 } & $<20 \%$ & 1.0 & - & & \\
\hline & $20-39 \%$ & 1.22 & 0.69 & 2.15 & 0.49 \\
\hline & $40-59 \%$ & 1.27 & 0.80 & 2.02 & 0.31 \\
\hline & $60-79 \%$ & 0.72 & 0.44 & 1.19 & 0.21 \\
\hline & $>79 \%$ & 0.76 & 0.33 & 1.74 & 0.52 \\
\hline \multirow[t]{5}{*}{ PGY-3 } & $<20 \%$ & 1.0 & - & - & \\
\hline & $20-39 \%$ & 1.04 & 0.56 & 1.93 & 0.90 \\
\hline & $40-59 \%$ & 0.75 & 0.46 & 1.22 & 0.25 \\
\hline & $60-79 \%$ & 0.94 & 0.55 & 1.59 & 0.81 \\
\hline & $>79 \%$ & 1.27 & 0.48 & 3.38 & 0.63 \\
\hline \multicolumn{6}{|l|}{ Patient characteristics } \\
\hline Gender & Male & 0.95 & 0.77 & 1.17 & 0.60 \\
\hline Age & $45-54$ & 1.09 & 0.74 & 1.59 & 0.66 \\
\hline \multirow{3}{*}{ (ref: $<45$ years) } & $55-64$ & 1.21 & 0.84 & 1.75 & 0.30 \\
\hline & $65-74$ & 1.06 & 0.69 & 1.63 & 0.80 \\
\hline & $75+$ & 1.06 & 0.67 & 1.70 & 0.79 \\
\hline \multirow[t]{6}{*}{ Comorbid conditions } & Coronary artery disease & 2.32 & 1.70 & 3.15 & $<0.001$ \\
\hline & Diabetes & 1.25 & 1.02 & 1.54 & 0.032 \\
\hline & Stroke & 1.07 & 0.66 & 1.73 & 0.78 \\
\hline & Hypertension & 1.03 & 0.83 & 1.27 & 0.80 \\
\hline & Hyperlipidemia & 1.12 & 0.91 & 1.39 & 0.29 \\
\hline & Tobacco use & 0.97 & 0.60 & 1.58 & 0.91 \\
\hline \multirow[t]{3}{*}{ Insurance (ref: private insurance) } & Medicare & 0.79 & 0.60 & 1.05 & 0.10 \\
\hline & Medicaid & 0.72 & 0.48 & 1.08 & 0.11 \\
\hline & Missing & 0.62 & 0.36 & 1.08 & 0.09 \\
\hline \multicolumn{6}{|l|}{ Resident characteristics } \\
\hline \multicolumn{2}{|c|}{ Resident is the patient's primary care provider } & 0.89 & 0.62 & 1.30 & 0.56 \\
\hline Practice & Practice B & 0.89 & 0.46 & 1.71 & 0.72 \\
\hline \multirow{2}{*}{ (ref: practice $\mathrm{A}$ ) } & Practice $\mathrm{C}$ & 0.46 & 0.25 & 0.86 & 0.02 \\
\hline & Practice D & 12.43 & 6.18 & 25.01 & $<0.001$ \\
\hline PGY level & PGY-2 & 2.07 & 1.28 & 3.35 & 0.003 \\
\hline (ref: PGY-1) & PGY-3 & 2.15 & 1.31 & 3.55 & 0.003 \\
\hline & 2008 & 0.33 & 0.12 & 0.89 & 0.03 \\
\hline \multirow[t]{3}{*}{ (ref: 2007) } & 2009 & 0.41 & 0.19 & 0.94 & 0.04 \\
\hline & 2010 & 0.28 & 0.12 & 0.64 & 0.003 \\
\hline & 2011 & 1.13 & 0.46 & 2.76 & 0.79 \\
\hline
\end{tabular}

Higher PGY level, however, was associated with higher brand-name statin prescribing (aOR 2.07, $95 \%$ CI $1.28-3.35, \mathrm{p}=0.003$, for PGY-2 and aOR 2.15, 95 $\%$ CI $1.31-3.55, p=0.003$, for PGY-3, compared to PGY-1). Other factors associated with brand-name statin prescribing by the residents were diagnoses of coronary artery disease (OR 2.32, $95 \%$ CI $1.70-3.15, \mathrm{p}<0.001$ ) and diabetes (OR 1.25, $95 \%$ CI 1.02-1.54, p $=0.032$ ), cohort year, and practice location (Table 3 ). The findings from sensitivity analyses using an alternative definition of refills were consistent (Table 4).

Figure 2 shows the adjusted predicted probabilities of a resident prescribing a brand-name statin by the rate of brandname statin prescribing of the supervising attending and by resident PGY level. For PGY-1 residents, the probability of a resident prescribing a brand-name statin ranged from $22.6 \%$ (95\% CI 17.3-28.0\%, p 0.001) for residents supervised by an attending who prescribed $<20 \%$ brand-name statins in the previous quarter, to $41.6 \%$ (95\% CI $24.6-58.5 \%, \mathrm{p}<0.001)$ for residents supervised by an attending who prescribed at least $80 \%$ brand-name statins in the previous quarter. For PGY-2 and PGY-3 residents, we observed no consistent pattern in the adjusted predicted probability of a resident prescribing a brand-name statin with increasing rates of brand-name prescribing by the supervising attending.

\section{DISCUSSION}

While most educators would agree that attending supervision affects resident practice, few studies have examined the effect of attending practice on resident prescribing behavior. In ambulatory resident clinics affiliated with two East Coast urban academic medical centers, residents and attending physicians prescribed brand-name statins in approximately one-fourth of encounters during which statin therapy was initiated for a patient, although rates varied across clinics. Generic vs. brand-name statin prescribing rates varied greatly across individual physicians, and the more senior residents prescribed brand-name medications at higher rates than interns. 
Table 4 Effect of Supervising Attending's Brand-Name Statin Prescribing Rate on the Odds of a Brand-name Statin Prescribed by the Resident, Excluding Encounters with Any Prior Statin Use $(n=2406)$

\begin{tabular}{|c|c|c|c|c|c|}
\hline \multirow{2}{*}{$\begin{array}{l}\text { PGY level of resident } \\
\text { PGY-1 }\end{array}$} & $\begin{array}{l}\text { Brand-name prescribing rate of } \\
\text { supervising attending }\end{array}$ & \multirow{2}{*}{$\begin{array}{l}\text { OR } \\
1.0\end{array}$} & \multicolumn{2}{|c|}{$95 \% \mathrm{CI}$} & \multirow[t]{2}{*}{ P-value } \\
\hline & $<20 \%$ & & - & - & \\
\hline & $20-39 \%$ & 1.53 & 0.84 & 2.76 & 0.16 \\
\hline & $40-59 \%$ & 2.33 & 1.36 & 3.99 & 0.002 \\
\hline & $60-79 \%$ & 2.45 & 1.38 & 4.34 & 0.002 \\
\hline & $>79 \%$ & 3.28 & 1.05 & 10.23 & 0.040 \\
\hline \multirow[t]{5}{*}{ PGY-2 } & $<20 \%$ & 1.0 & - & - & - \\
\hline & $20-39 \%$ & 1.20 & 0.67 & 2.14 & 0.54 \\
\hline & $40-59 \%$ & 1.31 & 0.81 & 2.11 & 0.27 \\
\hline & $60-79 \%$ & 0.81 & 0.48 & 1.36 & 0.43 \\
\hline & $>79 \%$ & 0.78 & 0.34 & 1.80 & 0.56 \\
\hline \multirow[t]{5}{*}{ PGY-3 } & $<20 \%$ & 1.0 & - & - & - \\
\hline & $20-39 \%$ & 1.05 & 0.55 & 2.00 & 0.88 \\
\hline & $40-59 \%$ & 0.78 & 0.47 & 1.29 & 0.33 \\
\hline & $60-79 \%$ & 0.93 & 0.54 & 1.61 & 0.79 \\
\hline & $>79 \%$ & 1.10 & 0.40 & 3.04 & 0.86 \\
\hline \multicolumn{6}{|l|}{ Patient characteristics } \\
\hline Gender & Male & 0.92 & 0.74 & 1.14 & 0.43 \\
\hline Age & $45-54$ & 1.13 & 0.76 & 1.67 & 0.54 \\
\hline \multirow[t]{3}{*}{ (ref: <45 years) } & $55-64$ & 1.23 & 0.84 & 1.79 & 0.29 \\
\hline & $65-74$ & 1.08 & 0.70 & 1.68 & 0.72 \\
\hline & $75+$ & 1.05 & 0.65 & 1.68 & 0.85 \\
\hline \multirow[t]{6}{*}{ Comorbid conditions } & Coronary artery disease & 2.22 & 1.62 & 3.05 & $<0.001$ \\
\hline & Diabetes & 1.23 & 1.00 & 1.52 & 0.05 \\
\hline & Stroke & 1.07 & 0.66 & 1.75 & 0.79 \\
\hline & Hypertension & 1.04 & 0.83 & 1.29 & 0.75 \\
\hline & Hyperlipidemia & 1.13 & 0.91 & 1.40 & 0.28 \\
\hline & Tobacco use & 0.85 & 0.51 & 1.42 & 0.54 \\
\hline \multirow[t]{3}{*}{ Insurance (ref: private insurance) } & Medicare & 0.77 & 0.58 & 1.03 & 0.08 \\
\hline & Medicaid & 0.69 & 0.46 & 1.04 & 0.07 \\
\hline & Missing & 0.54 & 0.30 & 0.96 & 0.036 \\
\hline \multicolumn{6}{|l|}{ Resident characteristics } \\
\hline \multicolumn{2}{|c|}{ Resident is the patient's primary care provider } & 0.96 & 0.65 & 1.41 & 0.82 \\
\hline Practice & Practice B & 0.81 & 0.40 & 1.63 & 0.55 \\
\hline \multirow[t]{2}{*}{ (ref: practice A) } & Practice $\mathrm{C}$ & 0.39 & 0.20 & 0.77 & 0.006 \\
\hline & Practice D & 10.99 & 5.25 & 22.99 & $<0.001$ \\
\hline \multirow[t]{2}{*}{ PGY level (ref: PGY-1) } & PGY-2 & 2.00 & 1.22 & 3.28 & 0.006 \\
\hline & PGY-3 & 2.11 & 1.26 & 3.55 & 0.005 \\
\hline Cohort year & 2008 & 0.34 & 0.13 & 0.93 & 0.035 \\
\hline \multirow[t]{3}{*}{ (ref: 2007) } & 2009 & 0.39 & 0.17 & 0.93 & 0.033 \\
\hline & 2010 & 0.27 & 0.11 & 0.65 & 0.003 \\
\hline & 2011 & 1.10 & 0.43 & 2.81 & 0.84 \\
\hline
\end{tabular}

We observed a relationship between residents' brandname vs. generic prescribing and the rate of brand-name prescribing of their supervising attending in the preceding quarter for PGY-1 but not for PGY-2 or PGY-3 residents. Furthermore, using longitudinal data from two institutions covering multiple practice sites, we found that practice site was an important predictor of brand-name prescribing, suggesting that institutional and local practice culture may play an independent role in residents' brand-name vs. generic prescribing. Collectively, our findings provide empirical support for the notion that training experience in particular bedside teaching by attending physicians during patient care may influence physician practice patterns. However, the findings of higher rates of brand-name prescribing by the more senior residents and the lack of a relationship between their prescribing and their attendings' practice patterns are concerning. The latter finding suggests that attending supervision plays a limited role in resident generic prescribing after the intern year, but that senior residents appear to prescribe generics at lower rates than interns. The mechanism behind higher brand-name prescribing rates by more senior residents is unclear, but literature on physician self-assessment suggests that the greatest disconnect between physician self-assessment and objective measures of competency occurs among physicians who are most confident and least competent. ${ }^{19}$ In this study, it is possible that senior residents believed that they were practicing cost-effective care in prescribing generic statins when in fact they were often not doing so.

Over the past three decades, the emphasis in graduate medical education has shifted from duty hours to supervision to competency-based evaluation. While the consequences of duty hours reform have been studied and documented extensively, little is known about the effect of supervision of residents by their attendings, and even less so in the ambulatory setting. The premise of value in increased supervision is that supervising attendings practice "better" medicine than their trainees. Overall, 

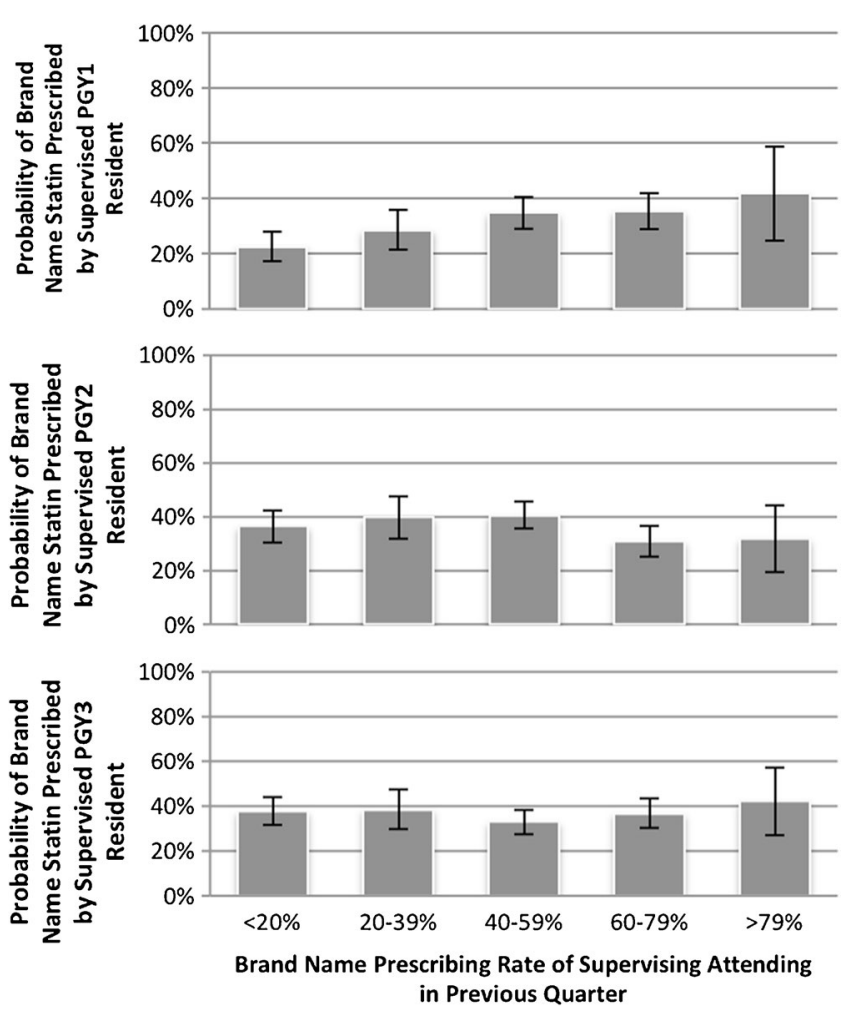

Fig. 2 Marginal probabilities of resident prescribing a brand-name statin by the supervising attending's brand-name statin prescribing rate for the previous quarter by PGY level. These figures show the adjusted predicted probabilities of a resident prescribing a brand-name statin by the level of brand-name statin prescribing by the resident's supervising attending and by resident PGY year. The $x$-axis represents the proportion of statin prescriptions that were written for brand-name statins by the supervising attending in the quarter preceding the encounter. The $y$-axis depicts the probability of the resident prescribing a brand-name statin while being supervised by the attending.

we did not observe evidence suggesting that attending physicians were prescribing generic statins at higher rates than the residents.

The recent Institute of Medicine report highlighted graduate medical education reform as a potential solution to geographic variation in physician practice patterns and quality of care delivered by the physician workforce. ${ }^{8}$ Variation in high-cost medication utilization has been described at the national and regional levels; for example, regional brand-name statin prescribing rates ranged from 29 to $60 \%$ in a report using Medicare Part $\mathrm{D}$ data. ${ }^{17}$ While the mean brand-name prescribing rates in our study were lower $(24.9 \%$ for residents and 25.7 $\%$ for attendings), we observed similar variation in the rate of brand-name statin prescribing across institutions and in brand-name statin prescribing across practice sites within the same institution and across individual physicians. Considering that brand-name prescribing accounts for billions in unnecessary healthcare costs, ${ }^{17,18}$ training residents to be cost-aware when prescribing has the potential to play an important role in reducing spending.

Despite the fact that some high-cost statins have lost patent protection, generic statin prescribing remains relevant as a model of cost-effective care in graduate medical education. Future studies should examine whether the effect we observed persists for other classes of medications, since studies of medication utilization have noted similar patterns of high-cost medication use across different classes of medications, including statins, antihypertensive medications, and antidepressants. ${ }^{17}$ These findings are important to medical educators as residency programs respond to the challenge of teaching cost-effective medicine and evaluating residents in this care competency. While most residents prescribed more generic than brand-name statins, some prescribed mostly brand-name medications. Novel approaches utilizing the electronic medical record such as default options may improve generic prescribing, ${ }^{20}$ and individualized electronic dashboards may help educators evaluate resident prescribing patterns and provide individualized feedback. Such tools would be useful to inform program directors' and residents' professional development and would provide objective information in the assessment of milestones adopted as part of the Next Accreditation System by ACGME. ${ }^{6}$

This study had limitations. Our use of observational data from two East Coast urban academic medical centers limits the internal and external validity of our conclusions. In particular, our findings may be confounded by unobservable variables including patient, attending, and resident characteristics associated with physician practice style that may have influenced the choice of statin but were not captured in our data, such as patient or cultural preferences and insurance or institutional formularies. For example, how frequently a resident works with a particular attending may influence the transfer of practice style and could be modified at the program level through scheduling changes. A prior study found that the medical school care intensity environment influenced resident prescribing of generic medications. ${ }^{12}$ Furthermore, although we aimed to study an aspect of physician behavior related to costeffective care, our findings may represent a more general relationship between attending and resident practice styles across other practice behaviors not related to cost. Availability of databases containing residency program scheduling, faculty, and resident characteristics and practice patterns would enable researchers to identify specific factors that influence these and other practice behaviors. Lastly, we cannot conclude causation from the observed association despite the temporal lag in attending relative to resident prescribing.

Our findings provide evidence of attending effect on resident practice of one specific example of costeffective care. The high variation in generic prescribing of statins in the academic setting points to room for improvement in generic prescribing by residents as well as their supervising attending physicians. Future research should identify factors that differentiate some attendings 
as more influential supervisors than others, as well as factors that identify which residents are more responsive to their supervisors' practice styles.

Acknowledgments: Contributors: The authors thank Dr. Susan Day and Steve Honeywell, Jr., for assistance with data collection.

Funders: Dr. Ryskina is supported by the Ruth L. Kirschstein National Research Service Award (NRSA) T32-HP10026. This study received no external funding.

Ethical approval: This study was reviewed and approved by the University of Pennsylvania and Weill Cornell Medical College Institutional Review Boards.

Conflict of Interest: The authors declare that they do not have a conflict of interest

Corresponding Author: Kira L. Ryskina, MD; Division of General Internal Medicine, Perelman School of Medicine University of Pennsylvania, 13-30B4 13th Floor Blockley Hall, 423 Guardian Drive, Philadelphia, PA 19104, USA (e-mail: ryskina@mail.med.upenn.edu).

\section{REFERENCES}

1. Kuehn BM. Economist: it's time for tough choices on US health costs. JAMA. 2014;311(24):2469-70.

2. Cooke M. Cost consciousness in patient care - what is medical education's responsibility? N Engl J Med. 2010;362(14):1253-5.

3. Weinberger SE. Providing high-value, cost conscious care: a critical seventh general competency for physicians. Ann Intern Med. 2011;155:386-8.

4. Korenstein D, Kale $\mathbf{M}$, Levinson $\mathbf{W}$. Teaching value in academic environments: shifting the ivory tower. JAMA. 2013;310(16):1671-2.

5. Detsky AS, Verma AA. A new model for medical education: celebrating restraint. JAMA. 2012;308(13):1329-30.

6. Caverzagie KJ, Iobst WF, Aagaard EM, et al. The internal medicine reporting milestones and the next accreditation system. Ann Intern Med. 2013;158(7):557-9.
7. Hackbarth G, Boccuti C. Transforming graduate medical education to improve health care value. N Engl J Med. 2011;364:693-5.

8. IOM (Institute of Medicine). Graduate medication education that meets the nation's health needs. Washington, DC: The National Academies Press: 2014

9. Wilensky GR, Berwick DM. Reforming the financing and governance of GME. N Engl J Med. 2014. doi:10.1056/NEJMp1406174.

10. Hayward RA, Manning WG, McMahon LF, Bernard AM. Do attending or resident physician practice styles account for variations in hospital resource use? Med Care. 1994;32:788-94.

11. Iwashyna TJ, Fuld A, Asch DA, Bellini LM. The impact of residents, interns, and attendings on inpatient laboratory ordering patterns: a report from one university's hospitalist service. Acad Med. 2011;86:139-45.

12. Ryskina KL, Pesko M, Gossey JT, Caesar EP, Bishop TF. Brand name statin prescribing in a resident ambulatory practice: implications for teaching cost-conscious medicine. Journal of Graduate Medical Education. 2014;6(3):484-8.

13. Mehrotra A, Reid RO, Adams JL, Friedberg MW, McGlynn EA, Hussey PS. Physicians with the least experience have higher cost profiles than do physicians with the most experience. Health Affairs. 2012;31(11):2453-63.

14. Good Stewardship Working Group. The "top 5" lists in primary care: meeting the responsibility of professionalism. Arch Intern Med. 2011;171(15):1385-90.

15. Jones P, Kafonek S, Laurora I, Hunninghake D. Comparative dose efficacy study of atorvastatin versus simvastatin, pravastatin, lovastatin, and fluvastatin in patients with hypercholesterolemia (the CURVES study). Am J Cardiol. 1998;81(5):582-7.

16. Stender S, Schuster H, Barter P, Watkins C, Kallend D, MERCURY I. Study Group. Comparison of rosuvastatin with atorvastatin, simvastatin and pravastatin in achieving cholesterol goals and improving plasma lipids in hypercholesterolaemic patients with or without the metabolic syndrome in the MERCURY I trial. Diabetes Obes Metab. 2005;7(4):430-8.

17. Donohue JM, Morden NE, Gellad WF, Bynum JP, Zhou W, Hanlon JT, Skinner J. Sources of regional variation in Medicare Part D drug spending. N Engl J Med. 2012;366:530-8.

18. Kale MS, Bishop TF, Federman AD, Keyhani S. "Top 5" lists top \$5 billion. Arch Intern Med. 2011;171(20):1856-8.

19. Davis DA, Mazmanian PE, Fordis M, Van Harrison R, Thorpe KE, Perrier L. Accuracy of physician self-assessment compared with observed measures of competence: a systematic review. JAMA. 2006;296(9):1094-102.

20. Patel MS, Day S, Small DS, Howell JT, Lautenbach GL, Nierman EH, Volpp KG. Using default options within the electronic health record to increase the prescribing of generic-equivalent medications: a quasiexperimental study. Ann Intern Med. 2014;161(10S):S44-52. 